\title{
Impact of sugar-sweetened beverage taxes on price, import and sale volumes in an island: interrupted time series analysis
}

\author{
Andrea M Teng ${ }^{1} \odot$, Murat Genç ${ }^{2}$, Josephine Herman ${ }^{3}$, Louise Signal ${ }^{1}$, Danny Areai ${ }^{3}$ \\ and Nick Wilson ${ }^{1, *}$. \\ 'Department of Public Health, University of Otago Wellington, 23 Mein Street, PO Box 7343, Wellington, New \\ Zealand: ${ }^{2}$ Department of Economics, University of Otago, Dunedin, New Zealand: ${ }^{3} T e$ Marae Ora Cook Islands \\ Ministry of Health, Avarua, Cook Islands, New Zealand
}

Submitted 31 May 2020: Final revision received 13 November 2020: Accepted 5 January 2021: First published online 18 January 2021

\begin{abstract}
Objective: To evaluate the impact of changes in import tariffs on sweetened beverages.

Design: Interrupted time series analysis was used to examine sweetened beverage tariff increases of 40-60\% in 2008 and to $75 \%$ in 2012, and an approximately $11 \%$ decrease in 2014 when an excise tax replaced the tariff. Post-tax trends were compared with a counterfactual modelled on the pre-tax trend for: quarterly price of an indicator beverage, monthly beverage import volumes (both 2001-2017) and quarterly sales volumes (2012-2017). In a controlled analysis, taxed beverage imports were compared with a sugary snacks control.

Setting: Cook Islands.

Participants: NA.

Results: In the first year, after the 2008 tariff increase the price of the selected indicator soft drink increased by $7 \cdot 3 \%$ (95\% CI 6.3\%, 8.3\%) but after the 2012 tariff increase it decreased by $13.9 \%$ (95\% CI $-14.9 \%,-12.8 \%)$. At the same time, the import volumes of taxed beverages decreased by $13.2 \%(95 \% \mathrm{CI}-38.1 \%$, $17.8 \%)$ and $2.9 \%(95 \% \mathrm{CI}-41.6 \%, 72.5 \%)$, respectively, and decreased by $24 \cdot 8 \%(95 \% \mathrm{CI}-36 \cdot 9,-9 \cdot 8)$ and $10 \cdot 2 \%(95 \% \mathrm{CI}-37 \cdot 1,37 \cdot 5)$ in the controlled analysis. After the 2014 tax decrease, the price of the indicator soft drink decreased by $23.6 \%$ (95\% CI $-26 \cdot 0 \%,-21 \cdot 1 \%)$, sweetened beverage imports increased by $4.5 \%$ (95\% CI $-39.5 \%, 156.0 \%)$ and sales of full-sugar soft drinks increased by $31 \%$ (95\% CI $-21 \%, 243 \%$ ).

Conclusions: The increased import tariffs on sweetened beverages appeared to be effective for reducing import volumes, but this was partly reversed by the reduced tax/tariff in 2014.
\end{abstract}

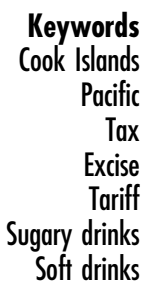

The WHO recommends sugar-sweetened beverages (SSB) taxes as one of the strategies to address the obesogenic environment ${ }^{(1-3)}$. Pacific Island countries and territories and other Small Island Developing States and middleincome countries have implemented a range of SSB tax regimes; however, few have evaluated its ability to reduce the consumption of SSB and improve diets ${ }^{(4-9)}$. While SSB excise studies in Tonga suggest some potential benefits from a public health perspective (with increased prices, reduced import volumes of taxed beverages and increased local bottled water and soft drink manufacturing) ${ }^{(4,10)}$, evidence is limited on whether SSB tax effects persist long term, how context impacts on consumer responses, which beverages people switch to and which types of SSB taxes are most effective ${ }^{(11)}$.

The Cook Islands is a self-governing, middle-income (World Bank 2016) Small Island Developing States in the Pacific region. It has a population of 17000 residents with an annual visitor population of 170 000. The Cook Islands has a high prevalence of obesity ( $62 \%$ of adults) and SSB consumption $^{(12,13)}$. Import tariffs on sweetened beverages (harmonised code (HS) 2202) were increased in 2008 and 2012 with the aim of addressing diabetes and oral health. Harmonised codes are used to categorise traded goods and are frequently used in tax administration. On 1 July 2008, a $40 \%$ tariff in place since $1979^{(14)}$ was replaced with 
a $60 \% \operatorname{tariff}^{(15)}$. At the end of July 2012, the tariff was increased to $75 \%{ }^{(16)}$, and in July 2013 this was increased to $77 \%{ }^{(17)}$. This two-percentage point change was unlikely to cause a detectable signal on study outcomes and therefore was not evaluated. On 1 July 2014, after a review of the tax structure in Cook Islands ${ }^{(17)}$, the sweetened beverage tariff was replaced with a nutrient-specific excise of $\mathrm{NZ}$ $\$ 9.37$ per $1 \mathrm{~kg}$ of sugar $^{(18)}$, equivalent to NZ\$0.94/1 (2018 US\$0.64/1) (using the $106 \mathrm{~g} / 1$ sugar content of CocaCola). The aim of the excise was to remain revenue neutral and align the SSB tax more closely with its rationale to reduce sugar consumption; however, this tax was an eleven percentage point decrease compared with the existing tariff (see the 'Results' section). For the first time, locally manufactured beverages were included, although implementation of this was incomplete and delayed. The excise applied to all sugar-sweetened waters (carbonated or not, HS 2202) but excluded juice, sachet drinks, fountain drinks and flavoured milk ${ }^{(18)}$. The excise removed SSB tax on beverages without sugar, such as artificially sweetened beverages (ASB).

Given this background, the current study aimed to examine the 1-year and 2-year impact of SSB tax changes in the Cook Islands on: (i) the shelf price of a selected indicator soft drink (can of Coca-Cola as a common and high profile brand); (ii) import volumes of taxed and untaxed beverages and (iii) sales of taxed and untaxed beverages (2014 only).

\section{Methods}

The study was an interrupted time series design comparing trends before and after tax changes.

\section{Data sets}

Cook Island Statistics Division, Ministry of Finance and Economic Development provided quarterly average price data (NZ\$) for a $355 \mathrm{ml}$ can of Coca-Cola from 2001 to 2017. This product is of sufficient popularity to be included in the consumer price index. These data were collected mid-quarter for calculating the consumer price index and the average prices across ninety retail outlets on the main island of Rarotonga. Coca-Cola range cans comprised $40 \%$ of soft drink and energy drink sales volumes (below) at a major supermarket from 2012 to 2017.

Monthly export volumes from New Zealand (the main trading partner) to the Cook Islands were obtained online from Statistics New Zealand (2001-2017). Beverage categories were sweetened beverages including full-sugar and zero-sugar soft drinks (HS 2202), juice (2009), milk (0401.00 and 0401.29) and water (2201, i.e. bottled water). The majority of imported sweetened beverages (98\% during the study period (UN Comtrade) ${ }^{(19)}$ ), milk (98\%), juice $(72 \%)$ and bottled water (67\%) were from New Zealand. New Zealand contributions to the total exports to the Cook Islands were extracted from the World Bank
UN Comtrade trade database for each year and product ${ }^{(19)}$. They were also applied as inverse weights to New Zealand export volumes to adjust for any shifts in country of origin that might have affected import trends. Missing data were approximated as the average of the earlier and later adjacent years. The usefulness of trade data as a measure of consumption depends on the market share of imported beverages compared with local manufacturing (for which there were no public data available) and locally made SSB, for example, sugar-sweetened fruit juices. Litter survey information from 2018 suggests approximately three-quarters of sweetened beverages were imported and the rest were locally manufactured (see the online Supplementary Material). Changes in production of local soft drinks could have an important influence on overall consumption but could not be measured here.

Annual sales volumes (litres) were provided by Cook Islands Trading Company from 2012 to 2017 for full-sugar beverages (carbonated full-sugar soft drinks, energy drinks full-sugar), low-sugar beverages (carbonated low-sugar soft drinks, low-sugar energy drink, flavoured water, e.g., ASB) and bottled water (imported and locally manufactured) (see online Supplementary Material for product details).

The Statistics Division also provided quarterly population projections, quarterly gross domestic product and monthly international visitor numbers (see online Supplementary Material for further information). Quarterly data were transformed into monthly figures for the trade analyses using the moving averages of the quarterly figures. Information from meetings with Cook Island expert stakeholders contributed to the contextual information in the interpretation of study results.

\section{Statistical analysis}

The size of the three major SSB tax changes was estimated and compared. The 2014 nutrient-specific excise tax (NZ\$/kg sugar) was transformed to an ad valorem equivalent $(\%, 2014)$ using the sugar concentration of the indicator soft drink (Coca-Cola; kg/l), UN Comtrade imported beverage values (US\$/1) ${ }^{(19)}$ and IMF exchange rates $(\mathrm{NZ} \$ / \mathrm{US} \$),{ }^{(20)}$ similar to what has been done elsewhere to estimate tax rates from trade databases. ${ }^{(21,22)}$

Interrupted time series with segmented regression was used to examine trends in taxed and untaxed beverages (where possible) for three key outcomes: (i) average price NZ\$, (ii) import volume (l/person per year) and (iii) sales volume ( $1 /$ person per year). Generalised least squares regression was used to model time series data and to allow for errors to be correlated and/or have unequal variances. Autocorrelation and moving averages were tested and adjusted for wherever this made a significant improvement in the model fit (lower AIC and $P<0.05$ from log-likelihood ratio test). Potential confounding by gross domestic product per capita (in $2016 \mathrm{NZ \$ )}$, monthly international visitor numbers and season/month was adjusted for, except for in 
the sales analysis where numbers were limited. Both absolute change and trend changes after each tax were modelled with all three taxes in the same statistical model. The absolute and relative difference (\% change) in outcomes in the first and second year after the tax change compared with the counterfactual were reported. The counterfactual was the expected model outcome based on existing pre-tax trends in the Cook Islands. Monte Carlo simulation was used to calculate $95 \%$ CI (see online Supplementary Material). Tax elasticities were calculated, that is, the percentage change in import volumes for a $1 \%$ change in the absolute tax level. All analyses were performed using $\mathrm{R}$ (version 3.4.3) in 2019.

Trends in sweetened beverage import volumes were also modelled compared with trends in a control group of sugary snack imports $(\mathrm{kg})$, selected due to their similarity as discretionary products, likely high sugar content, and because they were generally not subject to any increases in tariffs during the study period. Sugary snacks comprised a combination of sweets and chewing gum (1704), chocolate (1806.20-1806.90), biscuits and crackers (1905.20, 1905.30, 1905.31, 1905.32), cake (1905.90.0909) and ice cream (2105). A $12.5 \%$ import tariff on ice cream was removed on 1 April 2014, but this was not accounted for in the analysis. Sensitivity analyses were also used to test different model specifications (see online Supplementary Material for more information).

\section{Results}

\section{Tax changes}

The 2008 and 2012 tariff changes were both absolute increases of 20 and $15 \%$ percentage points in the tariff level, respectively (Table 1). However, the 2014 replacement of a tariff with an excise tax equated to an absolute
$11 \%$ percentage point decrease in the overall applied tax level on full-sugar soft drinks and for zero-sugar soft drinks there was an even larger decline.

\section{Price changes}

In the first year after the 2008 tariff increase, the price of an indicator soft drink (can of Coca-Cola) increased by $7.3 \%$ (95\% CI 6.3 8.3) compared with the counterfactual (Fig. 1 and see online supplementary material, Supplemental Table S4). However, after the 2012 tariff the price of the indicator beverage decreased by $13.9 \%$ (95\% CI $-14.9,-12.8)$. After the 2014 excise replacement, there was a larger decrease in the price of $23.6 \%$ (95\% CI $-26 \cdot 0,-21 \cdot 1)$. The average prices in the second year after each tax change were in the same direction but with different magnitudes (see online supplementary material, Supplemental Table S4).

\section{Imports}

In the first year after the 2008 tariff increase, there was a $13.2 \%(95 \% \mathrm{CI}-38 \cdot 1,17 \cdot 8)$ decline in imported volumes of sweetened beverages compared with the counterfactual and for the 2012 increase this figure was smaller at $2.9 \%$ (95\% CI -41.6, 72.5) (Fig. 2 and see online supplementary material, Supplemental Table S5). After the smaller 2014 excise was introduced, the imported volumes of sweetened beverages increased by $4.5 \%$ (95\% CI $-39.5,156 \cdot 0)$. The tax elasticities for these three figures were -0.66 (95\% CI $-1.91,0.89),-0.19(95 \% \mathrm{CI}-2 \cdot 77,4.83)$ and $-0.42(95 \%$ CI $-14.58,3.69)$, respectively, all with wide CI. In the second year after the 2008 tariff increase, there was an even greater decline in import volumes of $21.3 \%(95 \%$ CI -40.4, 3.6); however, in the second year after the 2012 and 2014 tax changes, the observed first year changes in

Table 1 Sweetened beverage tax changes in the Cook Islands by year and beverage type

\begin{tabular}{|c|c|c|c|c|c|c|}
\hline Year & Tax changes & Beverage category & $\begin{array}{l}\text { Import } \\
\text { unit value } \\
\text { in year of } \\
\text { change } \\
\text { (NZ\$/I) }\end{array}$ & $\begin{array}{l}\text { Size of the } \\
\text { previous tax } \\
\text { (\%/AVE) }\end{array}$ & $\begin{array}{l}\text { Size of the } \\
\text { new tax } \\
\text { (\%/AVE) }\end{array}$ & $\begin{array}{l}\text { Tax change (AVE, } \\
\text { percentage points) }\end{array}$ \\
\hline 13 August 2008 & Tariff $40 \% \rightarrow 60 \%$ & $\begin{array}{l}\text { Sweetened beverages, } \\
\text { including flavoured milk } \\
\text { HS } 2202\end{array}$ & $\$ 0.50 / 1$ & $40 \%$ tariff & $60 \%$ tariff & $20 \%$ \\
\hline End Jul 2012 & Tariff $60 \% \rightarrow 75 \%$ & $\begin{array}{l}\text { Sweetened beverages, } \\
\text { including flavoured milk } \\
\text { HS } 2202\end{array}$ & $\$ 0 \cdot 82 / 1$ & $60 \%$ tariff & $75 \%$ tariff & $15 \%$ \\
\hline \multirow[t]{2}{*}{1 Jul 2014} & $\begin{array}{l}\text { Tariff } 77 \% \rightarrow \text { excise NZ } \\
\$ 9.37 / \mathrm{kg} \text { of sugar }\end{array}$ & $\begin{array}{l}\text { Sweetened beverages, with } \\
\text { sugar } \\
\text { HS } 2202\end{array}$ & $\$ 1 \cdot 24 / 1$ & $77 \%$ tariff & $66 \%$ AVE $^{*}$ & $-11 \%$ \\
\hline & Tariff $77 \% \rightarrow 0 \%$ & $\begin{array}{l}\text { Sweetened beverages with } \\
\text { no sugar (e.g., ASB) } \\
\text { HS } 2202\end{array}$ & $\$ 1 \cdot 24 / I$ & $77 \%$ tariff & $0 \%$ tariff & $-77 \%$ \\
\hline
\end{tabular}

AVE, ad valorem equivalent; ASB, artificially sweetened beverage.

*The AVE is calculated as the ratio between the excise tax and the import unit value. The size of the excise is calculated by calculating the excise tax for the indicator soft drink (Coca-Cola) with $10.6 \mathrm{~g}$ sugar $/ 100 \mathrm{ml}$ as sold in the main island of Rarotonga. The unit value is from UN Comtrade exports to the Cook Islands, measured in US $\$ /$ and transformed to NZ\$/I using the IMF exchange rate. The AVE tax change is simply the difference between the size of the old tax and the new tax, measured in percentage points and as a relative change. 
Impact of sugar-sweetened beverage taxes

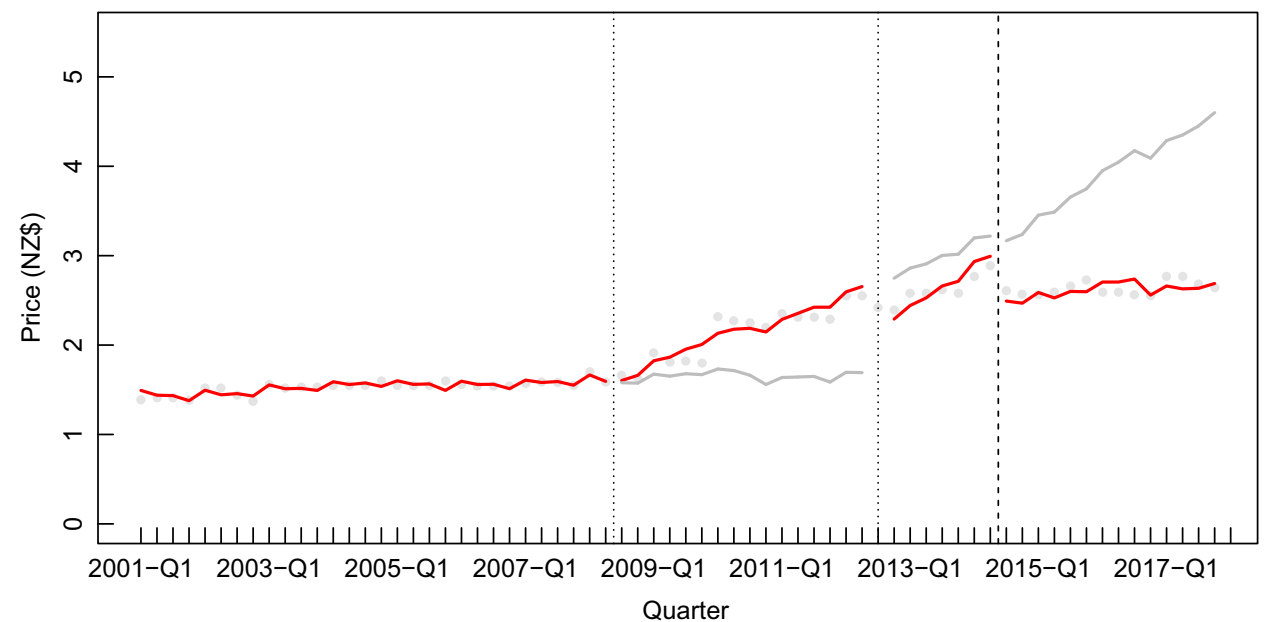

Fig. 1 (colour online) Impact of import tariff increases in the Cook Islands for 2008 (20\%) and $2012(15 \%)$ and decreased tax level in 2014 (by $11 \%$ ) on the average price of an indicator soft drink (355 ml can of Coca-Cola), 2001-2017. Data are from the Statistics Division, Ministry of Finance and Economic Management, Cook Islands. Analysis was adjusted for existing time trends, autocorrelation, GDP per capita, international visitor numbers and seasonality. Vertical dotted lines indicate tariff increases of 20 and $15 \%$ points in 2008 and 2012, respectively. The vertical dashed line was the introduction of the excise tax with a decrease of $11 \%$ points in the tariff/tax level. __ Price of a can of Coco-Cola; _ $\_$, expected price per can with no tax change

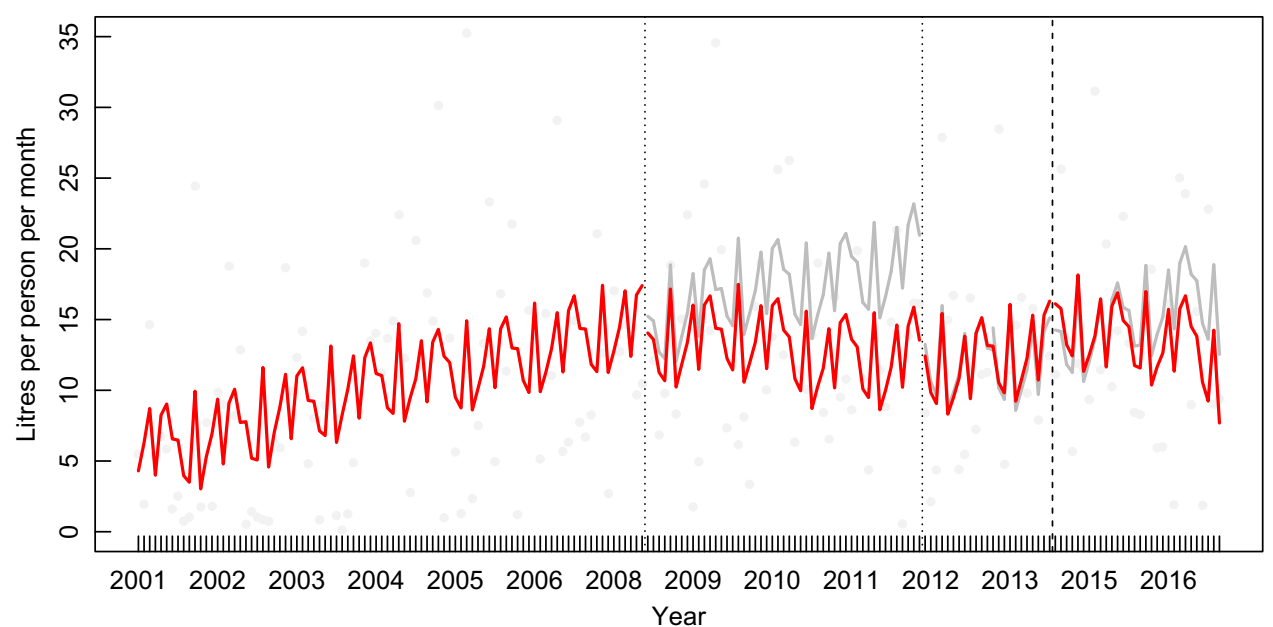

Fig. 2 (colour online) Impact of import tariff increases in the Cook Islands in 2008 (20\%), 2012 (15\%) and decrease in tax level in 2014 (by $11 \%$ ), on taxed sweetened beverage exports to Cook Islands, 2001-2017. Data are publically available from Statistics New Zealand. Analysis was adjusted for existing time trends, autocorrelation, GDP per capita, international visitor numbers (Statistics Division, MFEM) and seasonality. New Zealand (NZ) exports were weighted to represent all UN Comtrade partner reported exports to the Cook Islands (0-2\% excluding 2005 which was $8 \%)$. These figures do not include local soft drink production, considered to be a small part of the sweetened drink market, but it may have changed over time. $\_$, Sweetened beverage imports; - , expected sweetened beverage imports if there was no SSB tax change

the import trends reversed (see online supplementary material, Supplemental Table S5).

There was little evidence of any substitution to milk or juice (see online supplementary material, Supplemental Figure S3 and Table S6), although we could not rule out some substitution to bottled water or local soft drink products. Instead, there were declines in import volumes of milk and juice after the 2008 tariff increase and of juice after the 2012 tariff increase (not statistically significant). Although not formally studied given the low market share (44\%), there was a suggestion that imported bottle water volumes increased after the 2008 and 2012 tariffs (see online supplementary material, Supplemental Figure S4).

In the controlled analysis, the declines in sweetened beverages after each tariff were larger and more precise: $-24 \cdot 8 \%(95 \% \mathrm{CI}-36 \cdot 9,-9 \cdot 8)$ in 2008 and $-10 \cdot 2 \%(95 \% \mathrm{CI}$ $-37 \cdot 1,37.5$ ) in 2012 (see online supplementary material, Supplemental Table S7 and Figure S5). Lead-in period and population change had important impacts on the model. 


\section{Sales volumes}

There were $31.0 \%(95 \% \mathrm{CI}-20 \cdot 7,242 \cdot 5)$ and $32.3 \%(95 \%$ CI $-39.5,625.8)$ increases in sales volumes of full-sugar beverages (soft drinks and energy drinks) in the first and second year after the 2014 excise, respectively (Table 2 and see online supplementary material, Supplemental Figure S6), although results were imprecise. The figures for low-sugar beverages were a 6.2\% (95\% CI -791.2, 648.9) decline in the first year and a $21.7 \%$ (95\% CI $-862 \cdot 1,696 \cdot 4)$ increase in the second year.

\section{Discussion}

\section{Tariff increase findings}

There was a significant $7 \%$ increase in price in the year after the 2008 import tariff increase, whereas after the 2012 tariff increase there was a significant $14 \%$ decrease in price and no pass-through of the tax increase. Opposite trends suggest that contextual factors may have been important. For example, the 2012 result may have been affected by 'split invoicing'. That is, the legal practice of recording soft drink packaging and liquid on separate invoices was used since the 1980s to reduce the amount of tax paid on SSB; however, it was revoked in September 2009 (Audit Office investigation, 2011) ${ }^{(23)}$, with likely substantially increased tariffs paid by the major importer and sole supplier of Coca-Cola. In 2010, there was a stepwise increase in the price of Coca-Cola (Fig. 1), a trend which subsequently contributed to a higher counterfactual price and lower detected price impact after the 2012 tariff increase.

The low impact of the 2012 tariff change was also reflected in taxed beverage import trends. The decrease was greater (13\% decrease) after the 2008 tariff than after the 2012 tariff ( $3 \%$ decrease), although both had wide CI and decreases were two-fold and three-fold greater in controlled analyses. This may have been influenced by the revoking of split invoicing, increased availability of 50+ community water stations since 2010 with freely available UV light treated and tested drinking water and possible increases in local soft drink production after the 2009 sale of the local soft drink manufacturing business, although we had no data to assess this. The corresponding tax elasticities (change in import volume for every $1 \%$ change in SSB tax) were -0.66 and $-0 \cdot 19$. These are less than many other SSB tax elasticities ${ }^{(22)}$, but similar to those seen in Barbados (elasticity -0.43 , with a $4.3 \%$ reduction in grocery sales after a $10 \%$ tax) and Berkeley, USA (average elasticity -0.49). Barbados, like the Cook Islands, relied on an ad valorem tax increase, which may have resulted in a smaller impact on volume (elasticity) than volumetric or nutrientspecific taxes. Low awareness of the tariff increases by the public may also have limited their signalling effect ${ }^{(24)}$.

Second year import trends were similar to the first year after the 2008 tariff increase but after the 2012 and 2014 tax

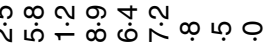

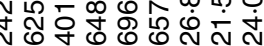
กีเด็ ஸे

ㅇ க் ஸ்่

เి

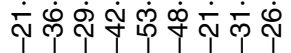

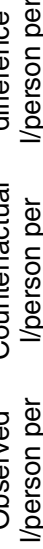

ஸ்

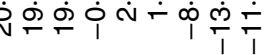
ळ

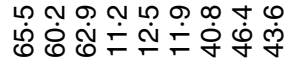


changes the first year changes reversed. Although imprecision affects these estimates, it is possible that changes in context factors over time can influence tax effects.

Fruit juice and milk import volume changes were mixed in response to SSB tariff changes and decreases suggest they were not important substitutes in the Cook Islands.

\section{Excise level decrease findings}

The changes related to the excise introduction were expected to be similar to tax subsidy studies reported elsewhere $^{(25)}$. Indeed, the price of the indicator beverage decreased significantly; there was an increase in sweetened beverage import volumes and in sales volumes of full-sugar beverages. Low-sugar beverage sales decreased slightly in the first year despite a large tax decrease but they increased in the second year. ASB may be less hazardous than $\mathrm{SSB}^{(26)}$; however, water is considered preferable for protecting health, particularly oral health. ASB substitution could be avoided by including ASB in the sweetened beverage tax regimen. The increases in imports and sales after the 2014 excise may have also been influenced by wider tax review changes in 2014 such as a decrease in income tax, an increase in social welfare payment levels, an increase in the minimum wage and an increase in consumption $\operatorname{tax}^{(17)}$. Overall, households were likely to have had more money available to spend on SSB, ASB and potential substitutes.

\section{Study strengths and limitations}

The current study is one of few SSB tax in evaluations conducted in a Pacific Island jurisdiction ${ }^{(4)}$ and Small Island Developing State ${ }^{(4,27)}$. The interrupted time series design allowed adjustment for existing trends and potential confounding. The study included up to 2 years of follow-up, compared three different tax changes (with both increased and decreased levels), used a within-country control and was interpreted in the light of contextual information from Cook Island-based experts. However, there was limited study power in the import and sales analyses given the large variation in month-to-month import volumes and the low number of sales data points. The sugary snack control was useful because these products were exposed to similar policies (except for SSB tax increases), availability and economic or environmental shocks; however, differences in marketing, popularity or shelf-life may also have affected trends and comparison with sweetened beverages. Price trends on a can of Coca-Cola are unlikely to fully represent the price changes of all beverages affected by the tax. Also, import and sales volumes do not fully equate to consumption in the short term, given potential waste and stockpiling. Sales in other grocery stores may have been affected differently compared with the major supermarket measured in the current study, for example, if they do not differentiate in price between low-sugar and full-sugar soft drinks. There were no data to examine trends in some potential substitute products such as locally manufactured soft drinks, tap water, flavoured milk, powdered drink sachets, soft drinks made from syrups, and local juice or bottled water. We could not distinguish differences in response between local residents and tourists with results representing both groups.

\section{Potential implications}

SSB taxes appear to have been a valuable tool for the Cook Islands in addressing increasing volumes of SSB imports, particularly the 2008 tariff increase. However, earlier decreases in expected import volumes were somewhat reversed after the 2014 excise change and SSB import volumes remained relatively high. SSB tax policies in the Cook Islands and elsewhere could be further strengthened for improved nutrition and health gains. SSB tax of at least $20 \%$ of shelf price is recommended for positive behavioural change ${ }^{(3)}$; however, further increases are likely to be needed for additional declines in SSB consumption and to maintain the level of tax with inflation for volumetric or nutrition-specific taxes. To avoid substitution to other unhealthy products, a SSB tax should ideally encompass a broad range of $\mathrm{SSB}^{(4)}$, including effective implementation of a SSB tax on locally produced beverages, while at the same time ensuring the availability of healthier alternatives such as bottled water and coconut water. Drinking water fountains and water-only policies in schools and the public provision of safe, tested and treated reticulated drinking water, are likely to be beneficial. For greater equity and public acceptance, SSB tax revenue could be hypothecated and invested into obesity prevention measures; health system capacity building and other interventions that benefit low-income households. Also, when a SSB tax increase is proposed, the change can be used as an opportunity to improve public awareness about the harms of SSB consumption, for example, via the mass media or even with a regulation requiring health warning labels on the beverages themselves ${ }^{(28)}$. Ongoing monitoring of SSB tax can help inform further changes that could strengthen implementation and enhance health benefits. Context and additional policy changes are important to consider because they can influence on SSB consumption and tax impact, for example, revoking of split invoicing in the Cook Islands. Involvement of health experts in SSB tax design ${ }^{(29)}$ and a multi-sectoral non-communicable disease (NCD) taskforce may strengthen the sustainability and implementation of obesity prevention policies ${ }^{(30,31)}$.

\section{Conclusions}

Although there was uncertainty in effect sizes, SSB tariffs appeared to have been a valuable tool for the Cook Islands in constraining SSB imports, particularly in 2008. 
The decline in SSB tax after the switch to SSB excise in 2014 appeared to reverse earlier gains and the existing policy could be strengthened for greater potential health gains.

\section{Acknowledgements}

Acknowledgements: The authors thank the numerous people in Cook Islands who provided support for this research via meetings, sharing resources and providing data required for the analysis, including employees of the Department of Statistics, Ministry of Health, Ministry for Finance and Economic Management and the Cook Islands Trading Corporation. The authors also thank Dr Dalice Sim from University of Otago for statistical support, and Dr Paula Vivili and Ms Elisiva Na'ati from the Pacific Community for support and facilitating contacts in the Cook Islands. Financial support: Funding for this research was received from the New Zealand Health Research Council (http://www.hrc.govt.nz/, grant 17/007) and the Otago Global Health Institute, University of Otago (for travel). Funders played no part in the study; collection, analysis and interpretation of data; writing the report and the decision to submit the report for publication. Conflict of interest: None. Authorship: A.M.T. conceptualised the study, facilitated data collection in the Cook Islands, carried out interviews and the litter survey, conducted the analysis, interpreted study results and wrote the first draft of the paper. J.H. and D.A. provided contextual information on the Cook Islands. L.S., N.W. and M.G. conceptualised the study and interpreted the study results. N.W. and M.G. supervised the analysis. All authors edited and approved the final manuscript. Ethics of buman subject participation: The study did not involve human subjects. Nevertheless, ethics approval was obtained from the University of Otago in February 2017 (F17/002); Te Marae Ora, Cook Islands Ministry of Health Research Committee on the 19 September 2017 and the Cook Island Research Committee on the 6 October 2017 (\#25/17). The study protocol is available online: http:// hdl.handle.net/10523/9432.

\section{Supplementary material}

For supplementary material accompanying this paper visit https://doi.org/10.1017/S1368980021000185

\section{References}

1. Backholer K, Vandevijvere S, Blake M et al. (2018) Sugarsweetened beverage taxes in 2018: a year of reflections and consolidation. Public Health Nutr 21, 3291-3295.

2. World Health Organization (2016) Report of the Commission on Ending Childhood Obesity. Geneva: World Health Organization.
3. World Health Organization (2016) Fiscal Policies for Diet and Prevention of Noncommunicable Diseases. Technical Meeting Report. Geneva: World Health Organization.

4. World Bank (2019) Using Taxation to Address Noncommunicable Diseases Lessons from Tonga. Washington, DC: Food and Agriculture Organization of the United Nations.

5. Alvarado M, Unwin N, Sharp SJ et al. (2019) Assessing the impact of the Barbados sugar-sweetened beverage tax on beverage sales: an observational study. Int J Behav Nutr Phys Activity 16, 13.

6. Colchero MA, Rivera-Dommarco J, Popkin BM et al. (2017) In Mexico, evidence of sustained consumer response two years after implementing a sugar-sweetened beverage tax. Health Aff 36, 564-571.

7. Colchero MA, Popkin BM, Rivera JA et al. (2016) Beverage purchases from stores in Mexico under the excise tax on sugar sweetened beverages: observational study. BMJ 352, h6704.

8. Colchero MA, Molina M \& Guerrero-López CM (2017) After Mexico implemented a tax, purchases of sugar-sweetened beverages decreased and water increased: difference by place of residence, household composition, and income level. J Nutr 147, 1552-1557.

9. Colchero MA, Guerrero-López CM, Molina M et al. (2016) Beverages sales in Mexico before and after implementation of a sugar sweetened beverage tax. PLoS One 11, e0163463.

10 Teng A, Puloka V, Genc M et al. (2020) Sweetened beverage taxes and changes in beverage price, imports and manufacturing: interrupted time series analysis in a middle-income country. Int J Behav Nutr Phys Act 17, 90.

11. Grummon AH, Lockwood BB, Taubinsky D et al. (2019) Designing better sugary drink taxes: tax the sugar, not the liquid. Science 365, 989-990.

12. Kessaram T, McKenzie J, Girin N et al. (2015) Overweight, obesity, physical activity and sugar-sweetened beverage consumption in adolescents of Pacific islands: results from the Global School-Based Student Health Survey and the Youth Risk Behavior Surveillance System. BMC Obes 2, 34.

13. Kessaram T, McKenzie J, Girin N et al. (2015) Noncommunicable diseases and risk factors in adult populations of several Pacific Islands: results from the WHO STEPwise approach to surveillance. Aust $N Z J$ Public Health 39, 336-343.

14. Cook Islands (1979) Import Levy (Amendment) Act 19781979. http://www.paclii.org/ck/legis/num_act/ilaa197879246/ (accessed October 2017).

15. Cook Islands (2008) Customs Tariff Amendment (Soft Drinks) Order 2008. https://www.usp.ac.fj/index.php?id= 13523 (accessed May 2018).

16. Wiseman D (2012) Cooks hikes tobacco and drink tariffs. In Radio New Zealand News International, 27/06/2012 ed.: Radio New Zealand Limited. https://www.rnz.co.nz/ international/pacific-news/205518/cooks-hikes-tobacco-anddrink-tariffs (accessed January 2021).

17. Cook Islands Government (2013) Cook Islands Government 2013 Tax Review. Cook Islands: Ministry of Finance and Economic Management.

18. Cook Islands (2016) Customs Tariff Schedule: Chapter 1 Chapter 24. http://www.mfem.gov.ck/images/documents/ RMD_Docs/Customs/Legislation/Customs_Tariff_Chapter_1__Chapter_24.pdf (accessed August 2018).

19. United Nations Commodity Trade Statistics Database Department of Economic and Social Affairs/Statistics Division (2018) UN Comtrade data. http://comtrade.un.org (accessed August 2018).

20. International Monetary Fund (2018) International Financial Statistics (IFS) Yearbook. https://www.elibrary.imf.org/ view/IMF041/25154-9781484354285/25154-9781484354285/ 25154-9781484354285.xml?language $=$ en (accessed January 2021). 
21. Stawowy W (2001) Calculation of ad valorem equivalents of non-ad valorem tariffs - methodology notes. Division on International Trade in Goods and Services, and Commodities UNCTAD. http://wits.worldbank.org/ witsweb/download/docs/AVEmeth.doc (accessed January 2021).

22. Teng AM, Jones AC, Mizdrak A et al. (2019) Impact of sugar-sweetened beverage taxes on purchases and dietary intake: systematic review and meta-analysis. Obes Rev 20, 1187-1204.

23. Wishart I (2013) Coca Cola Named in Multi Million Dollar Tax Haven Scam. Investigate Daily. Auckland: HATM Magazines Ltd.

24. Alvarez-Sanchez C, Contento I, Jimenez-Aguilar A et al. (2018) Does the Mexican sugar-sweetened beverage tax have a signaling effect? ENSANUT 2016. PLoS One 13, e0199337.

25. Bell C, Latu C, Coriakula J et al. (2020) Fruit and vegetable import duty reduction in Fiji to prevent obesity and noncommunicable diseases: a case study Public Health Nutr 23, 181-188.

26. Mandrioli D, Kearns CE \& Bero LA (2016) Relationship between research outcomes and risk of bias, study sponsorship, and author financial conflicts of interest in reviews of the effects of artificially sweetened beverages on weight outcomes: a systematic review of reviews. PLoS One 11, e0162198.

27. Alvarado M, Unwin N, Sharp SJ et al. (2019) Assessing the impact of the Barbados sugar-sweetened beverage tax on beverage sales: an observational study. Int J Behav Nutr Phys Act 16, 13.

28. Taillie LS, Reyes M, Colchero MA et al. (2020) An evaluation of Chile's Law of Food Labeling and Advertising on sugar-sweetened beverage purchases from 2015 to 2017: a before-and-after study. PLOS Med 17, e1003015.

29. Thow AM, Quested C, Juventin L et al. (2011) Taxing soft drinks in the Pacific: implementation lessons for improving health. Health Promot Int 26, 55-64.

30. World Bank (2014) NCD Roadmap Report: a Background Document on Preventing and Controlling NonCommunicable Disease in the Pacific. Forum Economic Finance Minister's Meeting July 2014. Washington, DC: World Bank Group.

31. Secretariat for Pacific Heads of Health Meeting (2018) Agenda Item: Pacific Monitoring Alliance For NCD Action Update. In Sixth Meeting of the Heads of Health, pp. 1-5 [F Sixth Meeting of The Pacific Heads of Health April 2018, editor]. Fiji: Pacific Heads of Health. 